\title{
Young people's knowledge, attitude, and behaviour on STI/HIV/AIDS in the context of Nepal: A systematic review
}

Upreti $D^{1}$, Regmi $\mathbf{P}^{1}$, Pant $\mathbf{P}^{1}$, Simkhada $\mathbf{P}^{1}$

${ }^{1}$ Section of Population Health, University of Aberdeen, United Kingdom

\begin{abstract}
Background: Sexual and reproductive health of young people has become a major health problem in recent decades. Recent and rapidly increasing Human Immune Deficiency Virus (HIV) rates show an urgent need for Sexually Transmitted Infections (STIs) and HIV prevention interventions in Nepal.

Objectives: This paper attempts to assess knowledge, attitude and behaviour on STIs/HIV/AIDS in the context of young peoples of Nepal.

Materials and methods: A systematic review based on the available literature was carried out including both qualitative and quantitative studies.

Results: Our findings indicate that the overall knowledge regarding STIs and HIV/AIDS is high although the level of knowledge seems to differ according to education, gender, and area of residence. Knowledge about condoms was also very high but practice of correct and consistent use in premarital and extramarital sexual relations with non-regular partners seems to be lower. The overall sexual behaviour among young people is unsafe.

Conclusion: This suggests that young people's sexual and reproductive health issues need to be further addressed and explored in order to promote safer and responsible sexual behaviour.
\end{abstract}

Key words: Attitude, Behaviour, HIV/AIDS, Knowledge, Nepal, STIs, Systematic Review, Young people

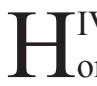
IV/AIDS is a global epidemic and is considered one of the greatest public health problems both in developed and developing world. Millions of people have already lost their life since it was first detected in the 1980 's ${ }^{1}$. It is also considered one of the most destructive epidemics recorded in the history of the world. The joint United Nations Programme on HIV/ AIDS estimates that there are 33.2 million people now living with HIV/AIDS worldwide and only in 2007; 2.5 million new cases were detected. Data also reveals that more than 16,000 new cases of HIV are detected every day and in every 14 seconds a youth is infected with HIV. Literature also claims that HIV/AIDS is also a leading cause of death in the developing countries ${ }^{1}$. In addition, in recent years, sexually transmitted infection is also rapidly increasing and also becoming most common infection among young people in both, developed and developing world ${ }^{2,3,4}$. This situation suggests that the issues of STIs/HIV/AIDS have to be treated as an emergency due to long-term consequences in demographic composition, and socio-economic aspect. HIV/AIDS is not only a problem of the health sector but it is directly associated with socioeconomic and demographic phenomenon of the nations ${ }^{5,6}$.
Though Nepal is considered as a "low-incidence" country in terms of HIV infection, recent seroprevalence data suggest that HIV/STIs infections have increased significantly in the last five years which is attributable to an active sex trades, low levels of condom use, increasing number of HIV among intravenous drug users and substantial male labour migration ${ }^{7,8,9}$ and there is a growing concern over young people in relation to the HIV and AIDS. Evidence also shows that many young people in Nepal involve in high risk sexual activities $^{7,8,9,10}$. This suggests that young people in Nepal are at risk for getting sexually transmitted infections including HIV/AIDS. However, the use of condom with non-cohabitating partners was found to have increased by more than $30 \%$ among youths (of age 15-24 years) in five years from 2001-2006, which reached to 78\% among these age groups ${ }^{10}$.

\footnotetext{
Correspondence

Dilip Upreti

Section of Population Health,

University of Aberdeen

Aberdeen, AB252ZD

United Kingdom

E-mail: d.upreti@abdn.ac.uk
} 
The most recent census of Nepal carried out in 2001 shows that adolescent and young people constitute a significant proportion $(32.48 \%)$ of the total population. Approximately one fourth of the total population (24 $\%$ ) is $10-19$ years old ${ }^{11}$. The HIV infection rate is also high among adolescents and youths, 4\% in the age group $15-19,19 \%$ in $15-24$ yrs age groups and $39 \%$ in 20-29 age groups ${ }^{12}$. These figures portray the patterns of HIV infection among different age groups. It is also documented that that youngsters in Nepal are engaged in premarital and unprotected sexual activities and still they don't consider themselves at risk because of widespread misinformation about the risk of AIDS ${ }^{13,14}$.

Evidence shows that HIV prevalence rate in Nepal is also concentrated (male $0.5 \%$ and female $0.3 \%$ ) among young people (10-24), who are considered as the active working and economically productive age group ${ }^{12,15}$. With such high prevalence in this important group of people, it is important to understand their knowledge, attitude, and behaviours about STI/HIV/AIDS. Though there are some studies looking at young people's knowledge, attitude, and behaviours on STI/HIV/AIDS, but there is no single systematic review published about young people's knowledge, attitude, and behaviours on STI/HIV/AIDS in the context of Nepal. Therefore, the main aim of the review was to examine the knowledge, attitude and behaviour on STIs/HIV/AIDS in the context of Nepal.

\section{Search strategy}

All papers published between 1997 and 2007 were searched systematically. Using Medical Sub-heading (MESH) terms and combinations of key words from relevant articles, initial searches were piloted and tested focusing on young people's knowledge, attitude, and behaviour on STI/HIV/AIDS and sexual health in Nepal. Ovid, MEDLINE, CINAHL and EMBASE were used to search the articles, which were limited to human, English language, related with adolescents and young people of age group 10-25 years. Auto alert was updated in each database for recently published articles. Similarly, handsearching of the grey and unpublished papers was also conducted. Organisational websites of World Health Organization, The Joint United Nations Programmes on HIV/AIDS, Department for International Development, Family Health International, National Centre for AIDS and STD Control, United National Children Fund were also viewed for the publication. In addition, Google and yahoo search engine were also used to access the relevant articles and reports.

The literature was searched using these key words: data collection, survey, cross-sectional studies, prospective studies, cohort studies, follow up studies, randomised trials, controlled clinical trials, random allocation, sexually transmitted disease, HIV/ or AIDS, adolescence, pregnancy in adolescence, sexual behaviours, contraceptive, condoms, epidemiology, family planning service, knowledge, attitude, practice, behaviours, sexual relation and intercourse.

\section{Identification of relevant studies}

We only included qualitative and quantitative research studies. In-depth interviews, focus group discussions, and case studies were used among the qualitative studies where as individual interviews, and self-administered questionnaires were used for quantitative research studies. All together, the possible obtained references were 963. Papers were selected in three different stages. Firstly papers were reviewed by title, then by abstract, and finally by full text. In each stage irrelevant papers were excluded based on the inclusion criteria. In the first stage, 268 potential papers were selected and 695 were excluded. These potential papers were reviewed by abstract and 165 were excluded and 103 eligible papers were selected. Again, abstracts of the selected 103 papers were reviewed in-depth and thoroughly and 76 were excluded which were not relevant to the research question and 27 papers were reviewed by full text. Out of 27 only 6 papers were included for this review and 21 were excluded due to the reasons of being double published or not relevant. Three more grey and unpublished papers were included by searching Yahoo, and Google search engines, web sites of different organisations, and hand searching.

\section{Quality assessment of studies}

Included papers were accessed for methodological quality using rating tools. All the included studies in the review were allocated quality scores based on assessment by reviewers according to the following criteria. Studies were allocated scores from 0 to 2 for each category $(0=$ poor, $1=$ moderate, and $2=$ strong $)$ and total scores added up for each study. Out of a score of 10 , study scoring less than 5 was poor quality, 5-7 was considered moderate quality and equal or greater than 8 were strong quality. Results after assessing the quality of the included papers using the rating tools found seven papers of strong quality, two papers of moderate quality.

\section{Results}

\section{Description of included studies}

Out of nine included studies, seven studies were related to knowledge, attitude and beliefs on STI/ HIV/AIDS, seven were about sexual behaviour, six studies were related to condom use, four were health seeking behaviour and five were risk perception. Basic characteristics of the studies are presented in Table 3. It has clearly noted that each study measured more than one outcome. 
All of these studies were directly related to STI/HIV/ AIDS including sexual and reproductive health of young people in different rural and urban places in Nepal at different time and in different groups. Three studies were conducted in school based settings ${ }^{16-18}$ and the rest six studies were community based ${ }^{7,19-23}$. All nine studies were cross-sectional studies. Target audiences of these studies were adolescents and youth of age 10-25 years, there was no racial, religious or gender discrimination to select the respondent, each and every person from a school or community has an equal chance for participation. Both qualitative and quantitative methods were used to conduct these researches. Study also found that some researchers also provided pen and paid envelope in which to seal their answer. A post box was also used for collection to maintain confidentiality and anonymity as well to increase response rate.

\section{Knowledge and attitude on STI/HIV/AIDS}

Seven studies $7,16,17,18,19,20,21$ looked at knowledge, and attitude on STIs/HIV/AIDS. Findings indicated that most of the young people had general knowledge about these infections ${ }^{7,16,17,18,19,20,21}$ and knowledge ranged from 54\% to $93 \%$. Knowledge seems to differ between education level, gender, and area of living. Strong associations have been found between levels of education and knowledge of HIV. Studies conducted in school based environments also showed high knowledge among young people about STI/HIV/AIDS ${ }^{16,17,18}$ compared with community based studies ${ }^{7,19,21}$.

Our review also found that females had low levels of knowledge compared with males (54\% Vs $87 \%)^{7}$. One school based study by Mahat $\mathrm{G}$ in Kathmandu valley found a statistically significant difference between levels of knowledge of HIV/AIDS in girls and boys (64 Vs $85, \mathrm{P}<0.05)^{16}$. We also found difference in knowledge among urban and rural males. Urban males were more aware and had more knowledge in all aspect of HIV/ AIDS than rural males ${ }^{21}$. However, rural females had more knowledge about STI and its symptoms compared with urban females $(67 \% \mathrm{Vs} 48 \%)^{21}$.

Most of the young people agreed that unsafe sex, sexual relations with multiple sex partners, sharing of needles/ syringes and mother to child infection were the most common modes of HIV transmission ${ }^{7,17,18,20,21}$. Different papers showed different levels of knowledge about mode of STI/HIV transmission. Knowledge of STI/HIV transmission through sharing of syringe/needle/blood and through unsafe sex ranged from $62 \%$ to $99 \%{ }^{16-18,20}$, and $28 \%$ to $97 \% 16,17,18,20$ respectively. Knowledge about modes of transmission also seemed to differ between genders and area of residence and education. One study and one report looked at gender differences for the modes of HIV transmission. Study reported that level of knowledge about modes of HIV transmission between girls and boys was quite different $(68 \%$ vs. $82 \%$, $\mathrm{P}=0.034)^{16}$, and another report showed that knowledge about mother to child transmission of HIV seems quite low among females $(46 \%)$ compared with males $(79 \%)^{7}$. A study conducted in the urban part of Nepal showed that urban people have more knowledge (88\%) about modes of HIV transmission ${ }^{20}$. Similarly, a school based study showed that young people who were attending school were more aware about modes of transmission compared with community based studies ${ }^{16,17,18}$.

Young people have low levels of knowledge in the area of prevention and perceived risk. A study reported that $78 \%$ agreed anal intercourse reduces the chance of getting HIV transmission and 92\% said that lambskin condoms could protect from HIV transmission ${ }^{16}$. Female sex workers, individuals with multiple sex partners, and intravenous drug users were the most common risk groups for HIV infection ${ }^{16}$. Regarding precautionary measures - participants believed avoiding sex with commercial sex workers, correct and consistent use of condoms, and maintaining sexual relation with only one partner were the best way to prevent STI/ HIV $^{7,19,20}$. Report showed vast differences on the level of knowledge between young male and female to avoid HIV by correct and consistent use of condom $(68 \%$ Vs $90 \%)^{7}$. Study participants also believed that person can look healthy and strong even if s/he carrying an HIV $^{7,19,20}$.

Over all knowledge about STI/HIV/AIDS, modes of transmission and ways of prevention noticeably varied among young people. Due to the reasons of education status, study environment (school and community based), gender based priority and area of living (urban and rural). Young people are at risk of getting STI/HIV/ AIDS although they have adequate knowledge of it.

\section{Condom use}

We found quite high overall knowledge about condoms among young people but practice of correct and consistent use in premarital and extramarital sexual relations with non-regular partners is low. Six studies were related to knowledge about condoms and condoms use behaviour ${ }^{7,18,19,21-23}$. Reports showed that knowledge about sources for condoms varies by gender, 97\% of young men and $85 \%$ of women know the sources of condoms, respectively. But only half of them said they could get it if they want ${ }^{7}$. Condoms should be removed from the penis when it is hard; only 37 and 20 percent of young men and women respectively knew this correctly $(p<0.000)^{19}$. Less than fifty percent of young people know that condoms couldn't be used more than once $^{19}$. More than three-quarters of boys and four-fifths of girls had not used any contraception in their first 
sexual intercourse, although they have a high level of knowledge ${ }^{22}$. Furthermore, $50 \%$ of boys and over $66 \%$ of girls had not used condoms in their recent sexual intercourse ${ }^{22}$.

Condoms use in first premarital sexual relations seemed different according to the area of living. Studies conducted in urban and rural setting showed that urban young people had a high practice for this compared to rural $(40 \% \mathrm{Vs} 30 \%)^{21}$. Less than five percent of young people used condoms in their pre-marital sexual $\operatorname{contact}^{18}$. Of those who have ever had sexual intercourse, $10 \%$ used condoms for the first time at age $15-19$ years, $9 \%$ used at age $22-24^{7}$. Condom used with a non regular partner is not common among young people ${ }^{23}$. Marital status determined different rates of condom use during sex with a non-regular partner. The study reported that unmarried young men looked like they were more conscious of using condoms during sex with non regular sex partners compared with married men $(43 \% \text { Vs } 31 \%)^{23}$

\section{Sexual behaviours}

Our review found that the overall sexual Behaviours among young people are unsafe. Sexual relations with commercial sex workers and non-regular partners are high, which is one of the major causes for STI/HIV/ AIDS transmission. Out of nine studies, seven studies were related to sexual behaviours, that is pre and extra-marital sexual relations, sexual relations with non-regular partners, and masturbation ${ }^{7,17,18,19,21,22,23}$. Two studies and one report showed that practice of premarital sexual intercourse varied according to gender, area of living, and study environment (school based and community based). Studies showed that more than $35 \%$ of unmarried boys and $15 \%$ unmarried girls were involved in premarital sexual intercourse, although it is strictly prohibited in Nepalese society ${ }^{22}$. Practice of pre and extra marital sexual relations with friend and commercial sex workers seemed quite low among students compared with factory workers and migrant people ${ }^{18,22,23}$. The report showed that premarital sexual relation seems quite high in rural communities compared to urban $(32 \% \mathrm{Vs} 13 \%)^{21}$. Education status makes differences for pre-marital sexual relations. The study showed that individuals with a high-level of education were less involved in premarital sex, but individuals with lower levels of education were highly active in premarital $\operatorname{sex}^{23}$.

Sexualrelation withnon-regularpartners is more common among married males compared with unmarried ${ }^{22,23}$. One study showed that marital status makes difference to visiting commercial sex workers. The study reported that the non-regular sex partner for $82 \%$ single and $50 \%$ married young men was a commercial sex worker ${ }^{23}$.
About half of the sexually experienced unmarried young people had their first sexual intercourse with a friend, $21 \%$ of unmarried young people kept their first sexual intercourse among boy and girl friends ${ }^{22}$. Nearly five percent of young people had at least two or more than two sexual partners excluding spouse and cohabiting partner ${ }^{7}$. Studies conducted in five major urban cities of Nepal found that about fifty percent of young unmarried males were sexually experienced ${ }^{22}$. Out of the sexually active married and unmarried respondents, over one in five boys and one in twenty girls reported sex with non-regular partner within the 12 months preceding the survey ${ }^{22,23}$. Use of alcohol and drug are significantly associated with the likelihood of engaging in risky sexual behaviour ${ }^{22}$.

More than sixty percent of young boys and girls believed that masturbation could damage ones health $(\mathrm{p}<0.01)$, and that a girl's hymen doesn't tear without sexual intercourse. Most of the (95\%) young men and women believed that having sexual intercourse during pregnancy can harm the foetus ${ }^{19}$. The median age for first sexual intercourse was 17 years $^{23}$. Sexual relation with commercial sex workers is high among school youth, that is $35 \%$, and $64 \%$ of youths keep their sexual relations with friend ${ }^{17}$.

\section{Health seeking behaviours}

We found that health seeking behaviours among young people is poor. Female and rural community people had very poor access to health services compared with male. In this review four different studies were related with health seeking behaviours ${ }^{7,20-22}$. More than $60 \%$ could reach nearest health service centre within half an hour, and preceding the date of survey $34 \%$ had visited the health facility ${ }^{22}$. Over 50\% unmarried young people used to share their health problem with other people prior to visiting the health service provider for treatment ${ }^{20}$. In the case of married female, approximately $80 \%$ shared it with spouse ${ }^{20}$. Discussion among spouses of prevention and treatment of STI/HIV/AIDS seemed quite low $^{7}$. Health seeking behaviour and discussion about reproductive health within the family and out side of the family among urban males is very high compared with rural males. It is just the opposite among females ${ }^{21}$, to talk about sex and sexuality is an issue of shyness in Nepalese society. However, urban females are more open and take part in the discussion of such topics compared with rural females ${ }^{21}$.

\section{Risk perception}

Five studies looked at risk perception regarding STI/ HIV/AIDS $7,16,19,22,23$. Adolescents and youths who were sexually active, migrant, and having a high school education (attending school) did not perceive themselves to be at risk of getting STI/HIV/AIDS ${ }^{16,22,23}$. 
There was no significant difference in perceived risk for getting STI/HIV/AIDS between those who did and did not have a non-regular sex partner in the previous 12 months before the study ${ }^{22}$. Misconception is the major cause for low risk perception although they performed the risky behaviours: like "The village girls or educated women can't be infected with STI and girls can't be pregnant in their first sexual intercourse" 22 . More than $89 \%$ of residents and $76 \%$ of non- resident young men who had regular sexual relations with non-regular partners said that they were free of risk of contracting STI/HIV/AIDS ${ }^{23}$. More than seventy percent young people believed that person can look healthy/strong, although he/she is carrying $\mathrm{HIV}^{7,19}$. Findings showed that overall young people did not perceive themselves to be at risk of contracting STI/HIV/AIDS although they were involved in casual sex.

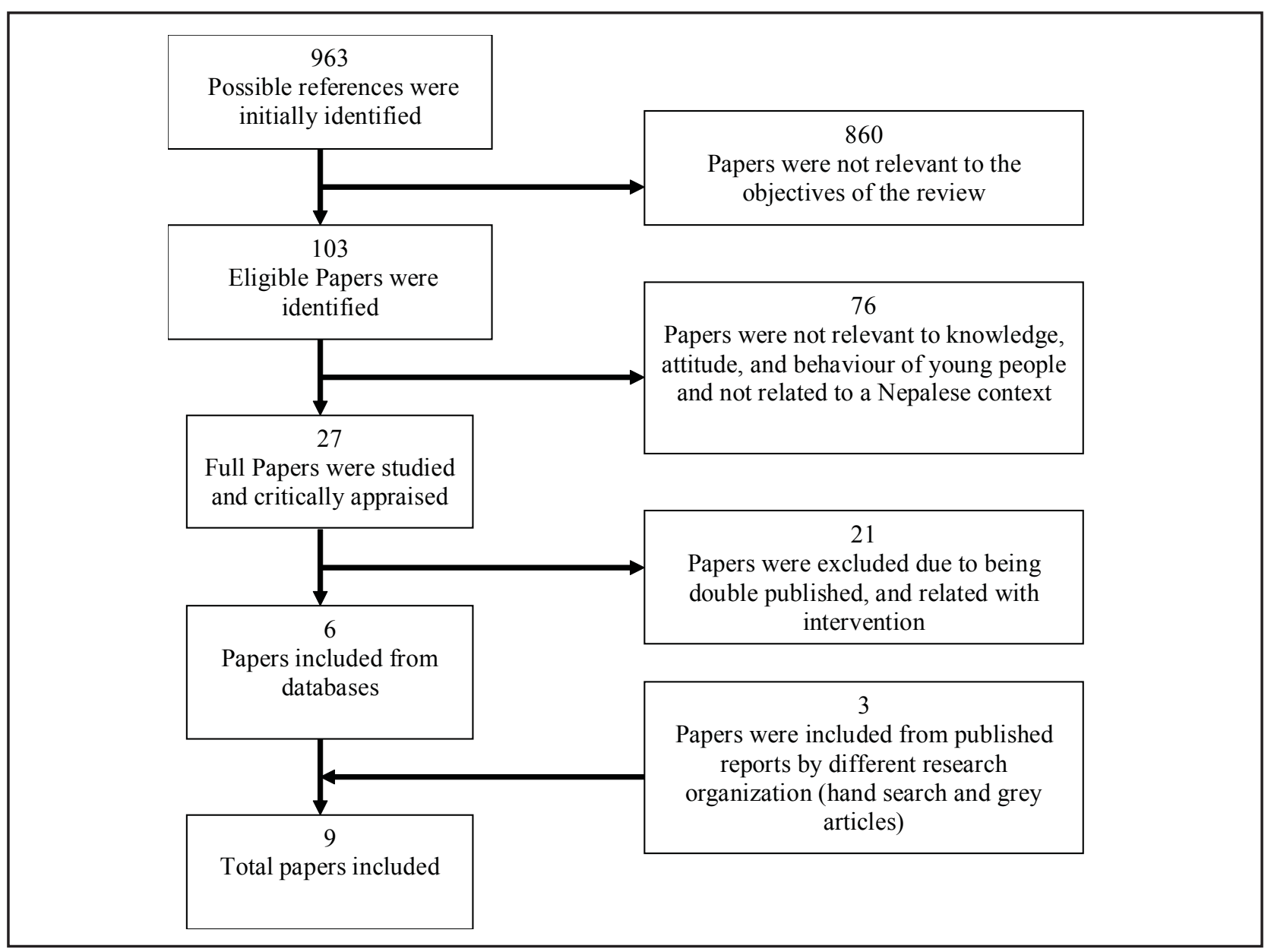

Fig 1: Flow chart of identification and selection of included studies

Table 1: Inclusion criteria

\begin{tabular}{|l|}
\hline Inclusion criteria \\
\hline Published after 1997, to March 2007 \\
\hline Peer review journal, published report by different I/NGO and grey reports \\
\hline Study should be related to the research purpose (knowledge, attitude and behaviour of young people in Nepal) \\
\hline Study should be done on human: Related to young people (10-25 years) \\
\hline Related to STI/HIV/AIDS and sexual health \\
\hline Single publication of a particular article in the English language \\
\hline Study can be related to young men or women or both \\
\hline Studies will be qualitative or quantitative or both \\
\hline
\end{tabular}


Table 2: Criteria for quality assessment

\begin{tabular}{|l|l|l|l|}
\hline Criteria for assessment & Poor (0) & Moderate (1) & Strong (2) \\
\hline Quality of the sample size & & & \\
\hline Validity and appropriateness of sampling methodology & & & \\
\hline Quality of reporting & & & \\
\hline Quality for generalisability of the result & & & \\
\hline Data analysis techniques (used statistical software) & & & \\
\hline Total & & & \\
\hline
\end{tabular}

Table 3: Basic characteristics of included studies

\begin{tabular}{|c|c|c|c|c|c|}
\hline Author/year & $\begin{array}{l}\text { Sample size / } \\
\text { methodology }\end{array}$ & $\begin{array}{l}\text { Location and } \\
\text { setting }\end{array}$ & Study design & Outcomes measured & $\begin{array}{l}\text { Quality of } \\
\text { the paper }\end{array}$ \\
\hline $\begin{array}{l}\text { Mahat et. al. } \\
2006\end{array}$ & $\begin{array}{l}\text { 150, purposive } \\
\text { sampling }\end{array}$ & $\begin{array}{l}\text { Urban area, } \\
\text { school based }\end{array}$ & Quantitative & $\begin{array}{l}\text { Knowledge attitude and belief, } \\
\text { risk perception }\end{array}$ & Moderate \\
\hline $\begin{array}{l}\text { Jaiswal et. al. } \\
2005\end{array}$ & $\begin{array}{l}\text { 1012, random } \\
\text { sampling }\end{array}$ & $\begin{array}{l}\text { Urban area, } \\
\text { school based }\end{array}$ & Quantitative & $\begin{array}{l}\text { Knowledge attitude and belief, } \\
\text { sexual behaviour }\end{array}$ & Strong \\
\hline $\begin{array}{l}\text { Stone et. al. } \\
2003\end{array}$ & $\begin{array}{l}\text { 1059, purposive } \\
\text { sampling }\end{array}$ & $\begin{array}{l}\text { Rural and } \\
\text { urban area, } \\
\text { community } \\
\text { based } \\
\end{array}$ & Quantitative & $\begin{array}{l}\text { Knowledge attitude and belief, } \\
\text { condom use, sexual behaviour, } \\
\text { risk perception }\end{array}$ & Strong \\
\hline Puri 2006 & $\begin{array}{l}1050 \text { for } \\
\text { quantitative study } \\
\text { and } 23 \text { in-depth } \\
\text { studies, used } \\
\text { random sampling }\end{array}$ & $\begin{array}{l}\text { Urban } \\
\text { area and } \\
\text { community } \\
\text { based }\end{array}$ & $\begin{array}{l}\text { Quantitative } \\
\text { and } \\
\text { qualitative }\end{array}$ & $\begin{array}{l}\text { Condom use } \\
\text { Health seeking behaviours } \\
\text { Sexual behaviours } \\
\text { Risk perception }\end{array}$ & Strong \\
\hline $\begin{array}{l}\text { Tamang et. al. } \\
2001\end{array}$ & $\begin{array}{l}326 \text { for quantitative } \\
\text { study and } 22 \text { in- } \\
\text { depth study, used } \\
\text { random sampling }\end{array}$ & $\begin{array}{l}\text { Urban area, } \\
\text { community } \\
\text { based }\end{array}$ & $\begin{array}{l}\text { Quantitative } \\
\text { and } \\
\text { qualitative }\end{array}$ & $\begin{array}{l}\text { Condom use } \\
\text { Sexual behaviour } \\
\text { Risk perception }\end{array}$ & Strong \\
\hline $\begin{array}{l}\text { Neupane et. } \\
\text { al. } 2003\end{array}$ & $\begin{array}{l}2824, \text { used stratified } \\
\text { two stage sampling } \\
\text { method }\end{array}$ & $\begin{array}{l}\text { Urban area, } \\
\text { community } \\
\text { based }\end{array}$ & Quantitative & $\begin{array}{l}\text { Knowledge/attitude/beliefs } \\
\text { Health seeking behaviour }\end{array}$ & Strong \\
\hline $\begin{array}{l}\text { New Era/ } \\
\text { MoH } 2007\end{array}$ & $\begin{array}{l}\text { 6004, stratified and } \\
\text { systematic sampling } \\
\text { techniques used. }\end{array}$ & $\begin{array}{l}\text { Rural and } \\
\text { urban area, } \\
\text { community } \\
\text { based }\end{array}$ & Quantitative & $\begin{array}{l}\text { Knowledge/attitude/beliefs } \\
\text { Condom use } \\
\text { Sexual behaviour } \\
\text { Health seeking behaviour } \\
\text { Risk perception }\end{array}$ & Strong \\
\hline $\begin{array}{l}\text { Mathur et. al. } \\
2004\end{array}$ & $\begin{array}{l}\text { 724, purposive } \\
\text { sampling method }\end{array}$ & $\begin{array}{l}\text { Rural and } \\
\text { urban area, } \\
\text { community } \\
\text { based }\end{array}$ & $\begin{array}{l}\text { Quantitative } \\
\text { and } \\
\text { qualitative }\end{array}$ & $\begin{array}{l}\text { Knowledge/attitude/beliefs } \\
\text { Condom use } \\
\text { Sexual behaviour } \\
\text { Health seeking behaviour }\end{array}$ & Strong \\
\hline $\begin{array}{l}\text { Lakhey et. al. } \\
2003\end{array}$ & $\begin{array}{l}210, \text { sampling } \\
\text { procedure was not } \\
\text { clearly mentioned }\end{array}$ & $\begin{array}{l}\text { Rural area, } \\
\text { School based }\end{array}$ & Quantitative & $\begin{array}{l}\text { Knowledge/attitude/beliefs } \\
\text { Condom use } \\
\text { Sexual behaviour }\end{array}$ & Moderate \\
\hline
\end{tabular}


Table 4: Description of outcomes

\begin{tabular}{|c|l|c|}
\hline S.N. & Outcome variable & Number of papers \\
\hline 1. & Knowledge/attitude/ behaviour & 7 \\
\hline 2. & Condom use & 6 \\
\hline 3. & Health seeking behaviour & 4 \\
\hline 4. & Sexual behaviour & 7 \\
\hline 5. & Risk perception & 5 \\
\hline
\end{tabular}

\section{Discussion}

Findings from this review show that the majority of the Nepalese young people had general knowledge on STI/HIV/AIDS, however the attitude and behaviours towards sexual health and HIV/AIDS was relatively poor. They were involved in unsafe and risky sexual behaviours (low rate of correct and consistent condom use, and they had multiple and non-regular sex partners), in spite of adequate knowledge of STI/HIV/ AIDS and the consequences of infection. Knowledge, attitude, and behaviours seem quite different according to education, gender, and area of residence. Studies conducted in schools showed relatively high level of knowledge compared with community based studies however, overall knowledge in all aspects of STI/HIV/ AIDS is very low. The main reason for this variation of knowledge could be poor sex education, less practices of discussion of STI/HIV/AIDS at school, with parents and family members and among friends in Nepal. We also found low knowledge among rural students compared to urban students. This difference may be due to the fact that the basic infrastructure like electricity, media, and transportation are more available in urban areas which can be positively associated to increase the level of knowledge. Sexual behaviour of young people is one of the major factors which determine the trends of the HIV epidemic. We can see some differences; all young people who live in different communities adopt different socio-economic and cultural backgrounds. Thus, multiple community-based, culturally appropriate strategies, relevant to the peculiar needs of young people may be effective in increasing the level of knowledge and attitudes. Such multi-component strategies enhance the quality of available information and provide updated information about STI/HIV/AIDS and other sexual health problems.

Sexual behaviours among rural communities are at high risk for STI/HIV/AIDS infection, because they have high practices of premarital sexual relation but low practice of condom use compared with urban communities. Possible factors associated with this finding are; low level of knowledge among rural people, lack of entertainment measures except sexual relations, lack of availability and accessibility of condoms, and females having less participation in the decisions to use condom and other complications of unsafe sex. The same situation like; condom use variation with an urban area, age, ethnicity, gender, and other risk taking behaviours were found among young people in the USA ${ }^{24}$. Highrisk behaviours (non use of condoms and non-regular multiple sex partners) seemed quite high among young married people compared with unmarried. The majority of youngsters had not used condoms in their first sexual intercourse and in each and every sexual contact although they have adequate knowledge on it and they know the importance of using it. Findings from this review are consistent with studies from the USA ${ }^{24}$. Less than five percent of young people use a condom in their pre-marital sexual relations and low rates of condom use are found with non regular partners. Premarital sexual intercourse is not permitted in Nepalese society but more than 35 percent were involved in it.

Health seeking behaviour looks very poor and this may imply a high risk of transmission of infection. There can be a variety of reasons for this like; the health service system of Nepal is not so strong, there is a lack of youth friendly service centres for sexual and reproductive health, and lack of confidentiality on sensitive issues. Young people still have some myths and misconceptions about STI/HIV/AIDS. The majority of the young people agreed that lambskin condoms could protect from HIV transmission and that anal intercourse reduces the chance of getting STI/HIV/AIDS. Most of them believed that masturbation could damage one's health and having sexual intercourse during pregnancy can harm the foetus.

\section{Conclusion}

Sexual health and wellbeing of young people is a growing public health concern in Nepal. Though knowledge regarding STIs/HIV/AIDS is high, their regular involvement in unsafe sexual practices suggests that only knowledge cannot change the personal behaviour. Due to lack of understanding and ignorance of the consequences of their risky behaviour, young people are always at the forefront for risky sexual behaviour. They are not just at risk of infection; 
they also become potential sources of transmission. Findings of this review indicate that young people's sexual and reproductive health issues need to be further explored and evidence based interventions should be implemented to promote safer and responsible sexual and reproductive behaviour.

\section{Strengths and limitation the review}

This review was performed under the robust and explicit criteria for systematic review and it is based on methodology and guidelines from the Cochrane Collaboration. However this review has some limitations. The search strategy was designed to find articles within the limiting time period. Therefore, some potentially relevant studies might have been missed from this review that was not published in this time (1997- April 2007). As this review only covers young Nepalese people, it may not be generalised to other young people from a different setting. Within this period of review, mainly three electronic databases were searched (CINAHL, EMBASE, and Ovid MEDLINE). There is equal chance of missing some organisational report due to publication bias.

\section{References}

1. UNAIDS. AIDS Epidemic Update: December 2007. Geneva: Joint United Nations Programme on HIV/AIDS; 2007.

2. Weinstock H, Berman S, Willard C. Sexually Transmitted Diseases among American Youth: Incidence and Prevalence Estimates. Perspectives on Sexual and Reproductive Health. 2004; 36(1):6-10.

3. Brown AE, Sadler KE, Tomkins SE, McGarrigle CA, LaMontagne DS, Goldberg D, et al. Recent Trends in HIV and Other STIs in the United Kingdom: Data to the End of 2002. Sex. Transm. Infect. 2004;80:159-66.

4. Monroe K, Jones M, Desmond R, Hook E. Health-Seeking Behaviours and Sexually Transmitted Diseases among Adolescents Attending: An Urban Paediatric Emergency Department. Comprehensive Therapy. 2007;33(3):120-6.

5. Mahal A, Rao B. HIV/AIDS Epidemic in India: An economic Perspective. Indian J Med Res. 2003;121:582-600.

6. Veenstra N, Whiteside A. Economic Impact of HIV. Best Practice \& Research Clinical Obstetrics and Gynaecology. 2005;19 (2):197210.

7. New Era/Ministry of Health. Nepal Demographic and Health Survey. Kathmandu: New Era/Ministry of Health; 2006.
8. Puri M. Sexual Risk Behaviour and Risk Perception of Unwanted Pregnancies and Sexually Transmitted Diseases among Young Factory Workers in Nepal. Kathmandu: Center for Research on Environment Health and Population Activities; 2001.

9. UNAIDS. AIDS epidemic update: December 2005. Geneva: Joint United Nations Programme on HIV/AIDS; 2005.

10. Puri M, Busza J. In forest and factories: sexual behaviour among young migrant workers in Nepal. Culture, Health and Sexuality. 2004; 6(2):145-58.

11. Central Bureau of Statistics (CBS)/Nepal. Statistical Yearbook of Nepal 2001. Kathmandu: National Planning Commission; 2001.

12. National Centre for AIDS and STI Control (NCASC). Cumulative HIV and AIDS Situation of Nepal (14 June 2008). Kathmandu: Department of Health Services/Ministry of Health and Population; 2008.

13. United Nations Children Fund. A survey of teenagers in Nepal for Lifeskill Development and HIV/AIDS Prevention. Kathmandu: UNICEF; 2001.

14. World Health Organization. Reproductive Health Strategy to Accelerate Progress towards Attainment of International Development Goals and Targets. Geneva: WHO; 2004.

15. United Nations Children Fund. HIV/AIDS. [Updated 2007 Cited 2009 June 1]. Available from http://www.unicef.org/infobycountry/ nepal_nepal_statistics.html

16. Mahat G, Scoloven M. HIV/AIDS Knowledge, Attitude, and Beliefs among Nepalese Adolescents. Journal of Advanced Nursing. 2006;53(5):583-90.

17. Jaiswal S, Magar BS, Thakali K, Pradhan A, Gurbacharya DL. HIV/AIDS STI Related Knowledge, Attitude, and Practice among High school Students in Kathmandu Valley. Kathmandu University Medical Journal. 2005; 3(9):69-75.

18. Lakhey S, Lakhey M, Bhattarai M, Niraula SR, Singh GK. HIV/AIDS Related Knowledge, Attitude and Practice among High school Students in Eastern Nepal. Journal of Nepal Medical Association. 2003;149(42):276-9.

19. Stone N, Ingham R, Simkhada P. Knowledge of Sexual Health Issues Among Unmarried Young People in Nepal. Asia-Pacific Population Journal. 2003;18(2):33-54.

20. Neupane S, Nichols D, Thapa S. Knowledge and Beliefs about HIV/AIDS among Young 
People in Urban Nepal. Asia-Pacific Population Journal. 2003;18(4):39-50.

21. Mathur S, Mehta M, Malhotra A. Youth Reproductive Health in Nepal, Is Participation the Answer? Washington: International Centre for Research on Women; 2004.

22. Puri M, Cleland J. Sexual behaviour and perceived risk of HIV/AIDS among young migrant factory workers in Nepal. Journal of Adolescent Health. 2006;38:237-46.
23. Tamang A, Nepal B, Puri M, Shrestha D. Sexual Behaviour and Risk Perceptions among Young Men in Border Towns of Nepal. Asia-Pacific Population Journal. 2001;16(2):195-210.

24. Kirby D. HIV Transmission and Prevention in Adolescents. [Updated 2002 Cited 2006 Dec 12]. Available from http://hivinsite.ucsf.edu/ InSite?page $=\mathrm{kb}-07-04-03$ 